\title{
Long-Term Neuroadaptations Produced by Withdrawal from Repeated Cocaine Treatment: Role of Dopaminergic Receptors in Modulating Cortical Excitability
}

\author{
Lourdes Nogueira, Peter W. Kalivas, and Antonieta Lavin \\ Department of Neurosciences, Medical University of South Carolina, Charleston, South Carolina 29425
}

\begin{abstract}
Dopamine (DA) modulates neuronal activity in the prefrontal cortex (PFC) and is necessary for optimal cognitive function. Dopamine transmission in the PFC is also important for the behavioral adaptations produced by repeated exposure to cocaine. Therefore, we investigated the effects of repeated cocaine treatment followed by withdrawal (2- 4 weeks) on the responsivity of cortical cells to electrical stimulation of the ventral tegmental area (VTA) and to systemic administration of DA $\mathrm{D}_{1}$ or $\mathrm{D}_{2}$ receptor antagonists. Cortical cells in cocaine- and saline-treated animals exhibited a similar decrease in excitability after the administration of $\mathrm{D}_{1}$ receptor antagonists. In contrast, cortical neurons from cocaine-treated rats exhibited a lack of $\mathrm{D}_{2}$-mediated regulation relative to saline rats. Furthermore, in contrast to saline-treated animals, VTA stimulation did not increase cortical excitability in the cocaine group. These data suggest that withdrawal from repeated cocaine administration elicits some long-term neuroadaptations in the PFC, including (1) reduced $\mathrm{D}_{2^{-}}$ mediated regulation of cortical excitability, (2) reduced responsivity of cortical cells to phasic increases in DA, and (3) a trend toward an overall decrease in excitability of PFC neurons.
\end{abstract}

Key words: cocaine; prefrontal cortex; electrophysiology; excitability; dopaminergic receptors; in vivo

\section{Introduction}

The ventral tegmental area (VTA) provides the primary dopaminergic input to the prefrontal cortex (PFC), and VTA firing evokes tonic and phasic dopamine (DA) release (Grace, 2000). The short- and long-term actions of DA in the PFC of drug-naive animals have been well documented (for review, see Seamans and Yang, 2004). However, the long-term neuroadaptations produced in cortical activity and in the DAergic modulation of cortical activity by withdrawal from psychostimulants are not well explored.

Repeated treatment with cocaine alters various aspects of dopamine transmission in the PFC and subcortical structures. In vivo electrophysiological studies have reported that, after 2-3 weeks of cocaine withdrawal, membrane bistability normally observed in pyramidal cells is reduced (Trantham et al., 2002). Peterson et al. (2000) have shown that cortical neurons recorded from amphetamine-pretreated rats and withdrawn for $3 \mathrm{~d}$ show increased responsiveness to glutamate and decreased responsiveness to dopamine, suggesting that the medial PFC (mPFC) is transiently hyperexcitable during amphetamine withdrawal. Recently, Goto and Grace (2005) reported that repeated cocaine

\footnotetext{
Received April 20, 2006; revised 0ct. 12, 2006; accepted 0ct. 12, 2006.

This work was supported by National Institute on Drug Abuse Grants 14698 (A.L.) and 1 P50-DA15369 (P.W.K.) and National Institutes of Health Grant C06 RR015455. We thank Laurence Neely and Joe Vuthiganon for technical assistance.

Correspondence should be addressed to Dr. Antonieta Lavin, Department of Neuroscience, Medical University of South Carolina, Charleston, SC 29425. E-mail: lavina@musc.edu.

D01:10.1523/JNEUROSCI.3206-06.2006

Copyright $\odot 2006$ Society for Neuroscience $\quad$ 0270-6474/06/2612308-06\$15.00/0
}

administration disrupted the synaptic plasticity at hippocampal and prefrontal cortical inputs to the nucleus accumbens, and Brady et al. (2005) have shown that repeated methamphetamine administration can disrupt excitatory synaptic interactions in the nucleus accumbens. These studies, performed in intact, anesthetized preparations, indicate that, independently of the psychostimulant used, repeated treatment elicits long-term changes in cortical and subcortical activity.

In the present study, we assessed the effects of DA $D_{1}$ and $D_{2}$ receptor antagonists on the current-evoked and spontaneous excitability of pyramidal cells recorded in rats treated repeatedly with cocaine or saline and withdrawn for 2-4 weeks. Moreover, we evaluated the cortical responses to electrical stimulation delivered into the VTA. We hypothesized that repeated cocaine treatment followed by a relatively longer withdrawal period produces a long-term reduction in cortical excitability and will disrupt DAergic modulation of PFC. This hypothesis was evaluated using in vivo intracellular recordings from PFC pyramidal neurons in anesthetized rats.

\section{Materials and Methods}

Animal preparation. All animals were handled in accordance with the procedures outlined in the Guide for the Care and Use of Laboratory Animals published by the US Public Health Service, and the Medical University of South Carolina Animal Care and Use Committees approved the specific protocol. Subjects were male Sprague Dawley rats (Charles River Laboratories, Wilmington, MA), weighing 200-250 g at the start of the experiment. Animals were housed in pairs in a temperature-controlled colony room on a $12 \mathrm{~h}$ light/dark cycle (lights on at 7:00 A.M.), and food and water were available ad libitum. Animals were allowed to acclimatize to the colony room for 3-5 d after their arrival. 
A

$\mathrm{SCH} 233900.1 \mathrm{mg} / \mathrm{Kg}$

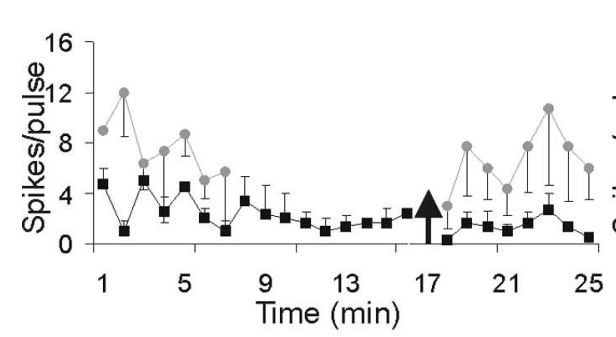

C

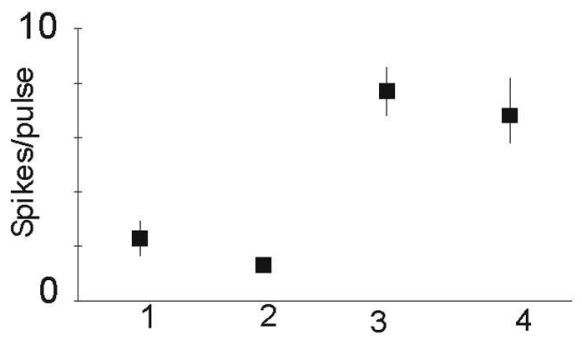

E

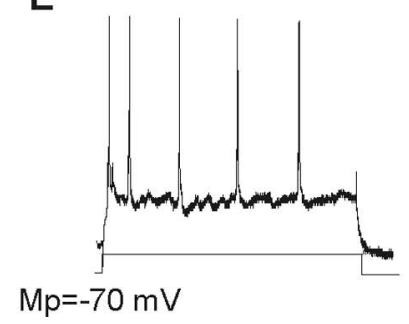

B

$\mathrm{SCH} 233901.0 \mathrm{mg} / \mathrm{Kg}$

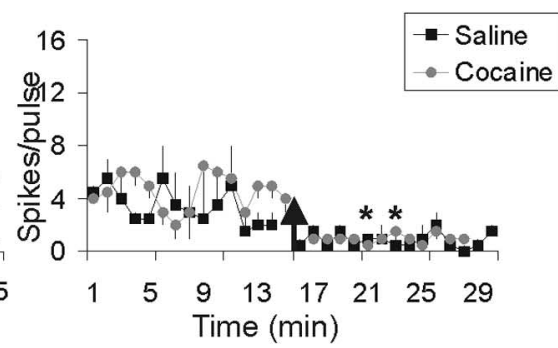

D
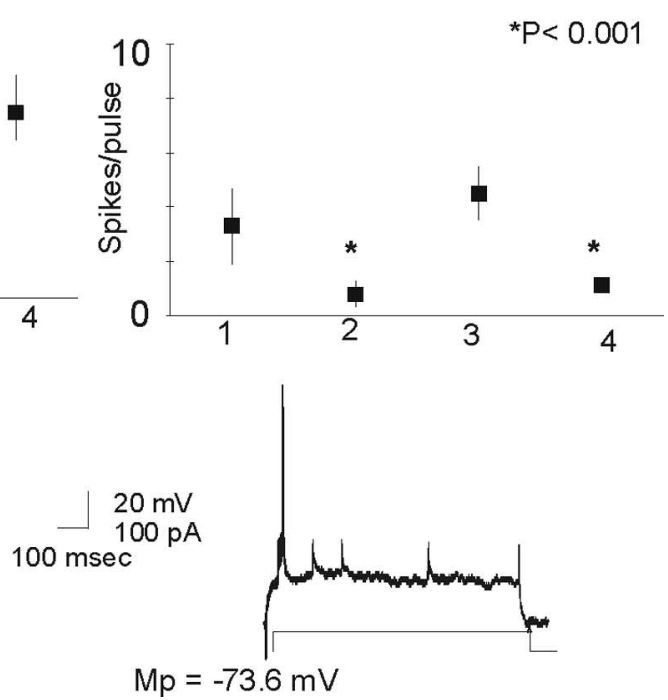

Figure 1. Effects of the $D_{1}$ receptor antagonist SCH 23390 in the current-evoked excitability of PFC neurons. $A$, Systemic administration of a low dose of SCH $23390(0.1 \mathrm{mg} / \mathrm{kg})$ produces a nonsignificant decrease in the current-evoked excitability of cortical cells recorded in saline-treated $(n=4)$ and cocaine-treated $(n=5)$ animals. Data are shown as mean \pm SEM per pulse. The arrow indicates administration of the drug. $\boldsymbol{B}$, Systemic administration of $\mathrm{SCH} 23390$ at $1.0 \mathrm{mg} / \mathrm{kg}$ produces a significant decrease in the current-evoked excitability of cortical cells recorded in saline-treated $(n=5)$ and cocaine-treated $(n=8)$ animals. Black squares, Saline animals; gray circles, cocaine animals. C, Graph summarizing the changes in current-evoked excitability elicited by $S C H 23390(0.1 \mathrm{mg} / \mathrm{kg})$ in the saline- and cocaine-treated groups. $D$, Graph summarizing the changes in current-evoked excitability elicited by $\mathrm{SCH} 23390(1.0 \mathrm{mg} / \mathrm{kg})$ in the saline- and cocaine-treated groups. 1, Saline baseline; 2, saline plus SCH23390; 3, cocaine baseline; 4, cocaine plus SCH 23390. $\boldsymbol{E}$, Representative traces of current-evoked excitability obtained in a cocaine-treated animal. The left trace illustrates the current-evoked spikes per pulse during a baseline recording; the right trace illustrates the current-evoked spikes after SCH $23390(1 \mathrm{mg} / \mathrm{kg})$. Mp, Membrane potential.

Cocaine hydrochloride was donated by National Institute on Drug Abuse (Baltimore, MD). Two groups of rats were used in the present study: a saline group, that received daily intraperitoneal injections of saline for $7 \mathrm{~d}$, and a group that was injected daily for $7 \mathrm{~d}$ with cocaine using a dosing regimen described previously to produce locomotor sensitization (Pierce et al., 1996; Bowers et al., 2004). On the first and last days of cocaine administration, the rats were injected intraperitoneally with $15 \mathrm{mg} / \mathrm{kg}$ cocaine. On the intervening days, the animals were injected intraperitoneally with $30 \mathrm{mg} / \mathrm{kg}$ cocaine.

Intracellular recordings in vivo. Rats were anesthetized with a mixture of ketamine/xylazine (30 and $25 \mathrm{mg} / \mathrm{kg}$, i.p., respectively) and placed in a stereotaxic apparatus. The cisterna magna was drained, and a hole was drilled over the PFC [coordinates from bregma: anteroposterior (AP), $3.2 \mathrm{~mm}$; lateral $(\mathrm{L}), \pm 0.6 \mathrm{~mm}$; ventral $(\mathrm{V}), 4-5.0 \mathrm{~mm}$ at $10^{\circ}$ inclination] (Paxinos and Watson, 1998) and VTA (from bregma: AP, $-4.9 \mathrm{~mm}$; , $\pm 0.5 \mathrm{~mm} ; \mathrm{V}, 7.7 \mathrm{~mm})$. Intracellular microelectrodes were pulled from Omegadot tubing (outer diameter, $1.5 \mathrm{~mm}$; World Precision Instruments, Sarasota, FL). The electrodes were filled with $3 \mathrm{~m}$ potassium acetate (electrode resistance, 25-40 $\mathrm{M} \Omega$ in situ). Impalements were defined as stable if the resting membrane potential was more negative than $-55 \mathrm{mV}$ and the action potential amplitude was at least $50 \mathrm{mV}$. A head- stage amplifier connected to a preamplifier (NEURODATA IR-283; Cygnus Technology, Delaware Water Gap, PA) amplified signals. Current was injected across a bridge circuit, with electrode potentials and current injection amplitude monitored on a personal computer screen using a National Instruments (Austin, TX) board as an interface to a computer running custom Labview software. Electrical stimulation of the VTA was delivered through bipolar concentric electrodes (model SNE-10; David Kopf Instruments, Tujunga, CA) delivering a train of pulses at $20 \mathrm{~Hz} / 2 \mathrm{~s}(2-6 \mathrm{~mA})$. Previously, we reported the effects of the same stimulation protocol in naive rats (Lavin et al., 2005).

After successful impalement of a cell, $10 \mathrm{~min}$ of stable baseline recordings were obtained before experimental recordings began. The spontaneous activity of the cells was recorded in bins of $10 \mathrm{~s}$, every $30 \mathrm{~s}$ throughout the experiment. The current-evoked excitability was recorded in bins of 1 s every $30 \mathrm{~s}$ throughout the experiment by passing a constant-current pulse ( $1 \mathrm{~s}$ duration) that evoked at least three action potentials during baseline recordings and maintaining that current through the rest of the experiment. Through all of the experiments, the membrane potential was monitored closely, and changes in $V_{\mathrm{m}}$ was corrected by addition of current via the recording electrode. The adjustment of membrane potential was performed only after VTA stimulation or drug administration, not during baseline.

Drugs were administered either intraperitoneally (sulpiride, 1.5 or $15 \mathrm{mg} / \mathrm{kg}$ ), or intravenously (SCH $23390[R(+)$-7-chloro-8-hydroxy3-methyl-1-phenyl-2,3,4,5-tetrahydro- $1 \mathrm{H}$-3benzazepine hydrochloride], 1 or $0.1 \mathrm{mg} / \mathrm{kg}$ ). The temperature of the animal was maintained at $36 \pm 0.5^{\circ} \mathrm{C}$ through a thermostatically controlled heating pad.

Histology and statistics. At the end of the experiments, the animals were given an overdose of anesthetic and perfused transcardially with saline, followed by $10 \%$ buffered Formalin. The brain was removed and placed in a solution of $15 \%$ sucrose at $4^{\circ} \mathrm{C}$. Coronal slices, $60 \mu \mathrm{m}$ thick, were cut using a freezing microtome and collected in phosphate buffer. The slices were stained with cresyl violet to aid in the localization of the electrode track and the stimulating electrode. The spontaneous and current-evoked firing of neurons recorded in the PFC was compared using a two-tailed, two-sample Student's $t$ test or ANOVA with repeated measures and post hoc Fisher's test. Statistical significance was set at $p<0.05$, and all results are presented as mean \pm SEM.

\section{Results}

Recordings were performed in the deep layers $(\mathrm{V}-\mathrm{VI})$ of the prelimbic and infralimbic PFC in 10 rats treated with saline and in 12 rats treated with cocaine. All neurons included in data analysis exhibited stable membrane properties for at least $25 \mathrm{~min}$ and fulfilled criteria of resting membrane potential, amplitude, and duration of action potentials. Thirteen neurons were recorded in the saline-treated group and 23 in the cocaine-treated group. Of the 13 cells recorded in salinetreated animals, five were silent $(38 \%)$ and six exhibited membrane bistability (46\%), and two neurons were firing in a tonic, nonbistable manner; the average rheobase current for 
evoked excitability was $100 \pm 18 \mathrm{pA}$. In the cocaine-treated group, 14 of 23 neurons were silent $(61 \%), 5$ of $23(22 \%)$ exhibited membrane bistability, and 4 of 23 neurons were firing in a tonic, nonbistable manner. The average rheobase current for evoked excitability was $120 \pm 15$ pA. Repeated cocaine administration did not significantly affect spike threshold (saline, $-49.1 \pm 3.2 \mathrm{mV}$; cocaine, $-50.9 \pm 3.4 \mathrm{mV}$ ), spike amplitude (saline, $61.1 \pm 4.3 \mathrm{mV}$; cocaine, $58 \pm 3.3 \mathrm{mV}$ ), or input resistance (saline, $71.3 \pm 11 \mathrm{M} \Omega$; cocaine, $60 \pm 14.1$ $\mathrm{mV}$ )

\section{Effect of DA receptor antagonists on cortical excitability}

In the absence of VTA stimulation, previous microdialysis studies reveal an in vivo level of extracellular DA in the 0.5-5.0 nM range (Hedou et al., 2001; Nakamura et al., 2001; Marsteller et al., 2002; Phillips et al., 2004). Modulation of the excitability of PFC neurons by this tonic background DA was revealed by recording the basal current-evoked excitability of the cell every $30 \mathrm{~s}$ for at least $10 \mathrm{~min}$, followed by systemic administration of either $\mathrm{D}_{1}(\mathrm{SCH}$ 23390 ) or $\mathrm{D}_{2}$ (sulpiride) receptor antagonists and subsequent measurement of current-evoked excitability every $30 \mathrm{~s}$ for at least another $10 \mathrm{~min}$.

Administration of low doses of $\mathrm{SCH}$ $23390(0.1 \mathrm{mg} / \mathrm{kg})$ elicited a nonsignificant decrease in the current-evoked excitability of cortical cells recorded in saline- and cocaine-treated animals $\left(F_{(1,13}\right)=3.1 ; p<$ $0.100)$ (Fig. $1 A$ ). There was a difference in the baseline firing between cocaine- and saline-treated animals for this particular group, but the results in both sets of animals showed the same trend.

Systemic administration of the selective $\mathrm{D}_{1}$ receptor antagonist SCH 23390 (1 $\mathrm{mg} / \mathrm{kg}$ ) produced a significant decrease in the current-evoked excitability of cortical cells recorded in saline- and cocainetreated animals. Data were evaluated using an ANOVA with repeated measures; the between-group factor was group (saline vs cocaine), and the repeated measure was treatment (baseline vs SCH 23390). The ANOVA revealed a main effects of group $\left(F_{(1,24)}=4.5 ; p=0.04\right)$ and SCH 23390 treatment $\left(F_{(1,24)}=126.9 ; p<0.0001\right)$ on intrinsic excitability; the group $\times$ treatment interaction reached the trend level $\left(F_{(1,24)}=\right.$ $3.2 ; p=0.08)$. The main effect of treatment indicated that $\mathrm{SCH}$ 23390 application reduced intrinsic excitability in both the control and cocaine groups (Fig. $1 B$ ).

Administration of the $\mathrm{D}_{2}$ receptor antagonist sulpiride (1.5 $\mathrm{mg} / \mathrm{kg}$ ) elicited a significant increase in the current-evoked excitability in the saline-treated group and no effect in the cocainetreated group (Fig. 2A). A repeated-measures ANOVA revealed

\section{B Sulpiride $15 \mathrm{mg} / \mathrm{Kg}$}

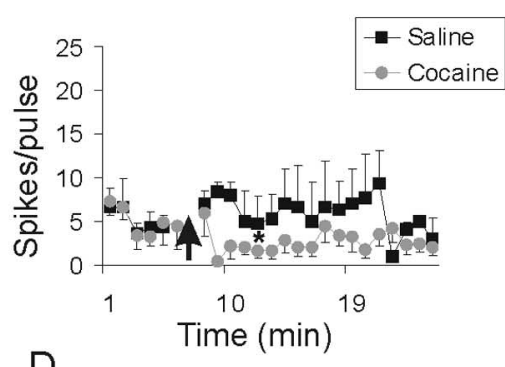

${ }^{*} p<0.009$

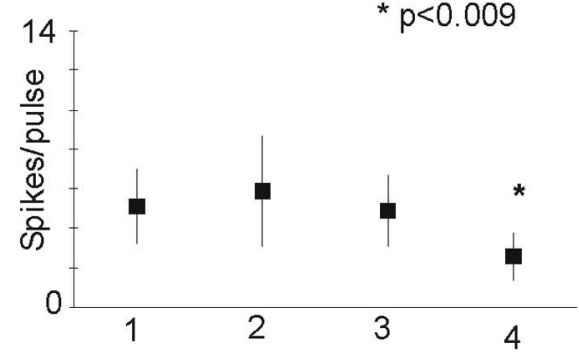

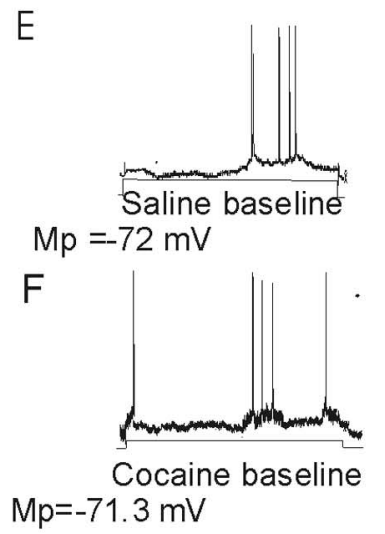

Figure 2. Effects of the $D_{2}$ receptor antagonist sulpiride in the current-evoked excitability of PFC neurons. $\boldsymbol{A}$, Systemic administration of sulpiride $(1.5 \mathrm{mg} / \mathrm{kg})$ produce a significant increase in the current-evoked excitability of PFC neurons recorded in saline-treated animals $(n=4)$, but it did not affect the excitability of cortical cells in cocaine-treated animals $(n=5)$. The arrow indicates administration of the drug. $\boldsymbol{B}$, High doses of sulpiride $(15 \mathrm{mg} / \mathrm{kg})$ produce an increase in the current-evoked excitability of PFC neurons recorded in saline animals $(n=3)$. However, in cocaine animals $(n=5)$, sulpiride $(15 \mathrm{mg} / \mathrm{kg})$ elicited a significant decrease in current-evoked excitability. C, Graph summarizing the changes in current-evoked excitability elicited by sulpiride (1.5 $\mathrm{mg} / \mathrm{kg}$ ) in the saline- and cocaine-treated groups. $\boldsymbol{D}$, Graph summarizing the changes in current-evoked excitability elicited by systemic administration of higher doses of sulpiride $(15 \mathrm{mg} / \mathrm{kg})$ in the saline- and cocaine-treated groups. 1, Saline baseline; 2 , saline plus sulpiride; 3 , cocaine baseline; 4 , cocaine plus sulpiride. $\boldsymbol{E}$, Representative trace of the current-evoked excitability in a saline-treated animal during baseline recording (left trace) and after administration of sulpiride (right trace). $\boldsymbol{F}$, Representative trace of the current-evoked excitability elicited in a cocaine-treated animal during baseline recording (left trace) and after sulpiride administration (right trace). Mp, Membrane potential.
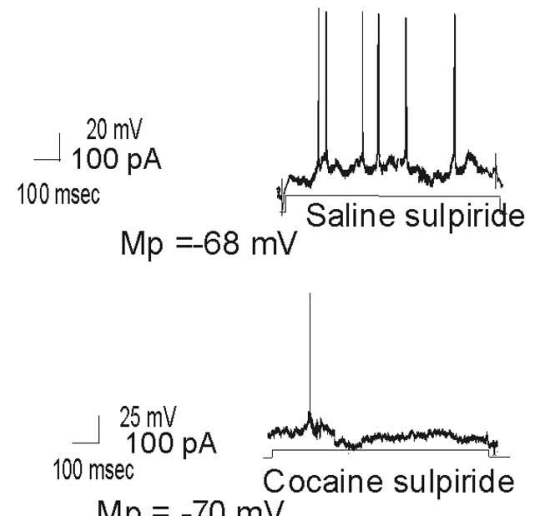

$\mathrm{Mp}=-70 \mathrm{mV}$
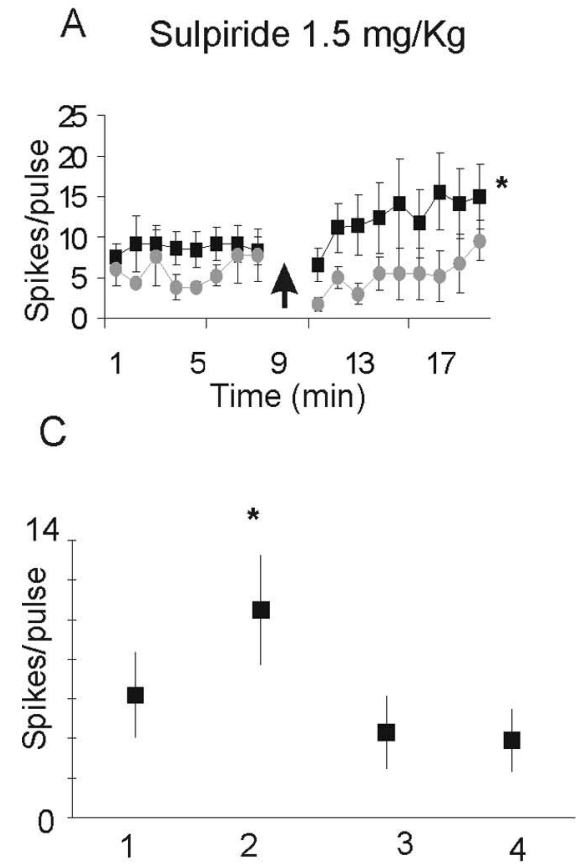

main effects of group $\left(F_{(1,22)}=24.7 ; p<0.0001\right)$, sulpiride treatment $\left(F_{(1,22)}=5.7 ; p=0.03\right)$, and a group $\times$ treatment interaction $\left(F_{(1,22)}=3.9 ; p=0.05\right)$. Post hoc analyses designed to decompose the interaction revealed a significant difference between cocaine and saline subjects in response to sulpiride $(p<0.001)$. The different results obtained with sulpiride in the saline- and cocaine-treated groups were not the product of recording some unusually excitable cells in the saline group, because sulpiride increased the average number of spikes in five of seven neurons by $86.6 \%$ and slightly decreased excitability in two of seven neurons by $35.6 \%$. Higher doses of sulpiride $(15 \mathrm{mg} / \mathrm{kg})$ elicited an 
A

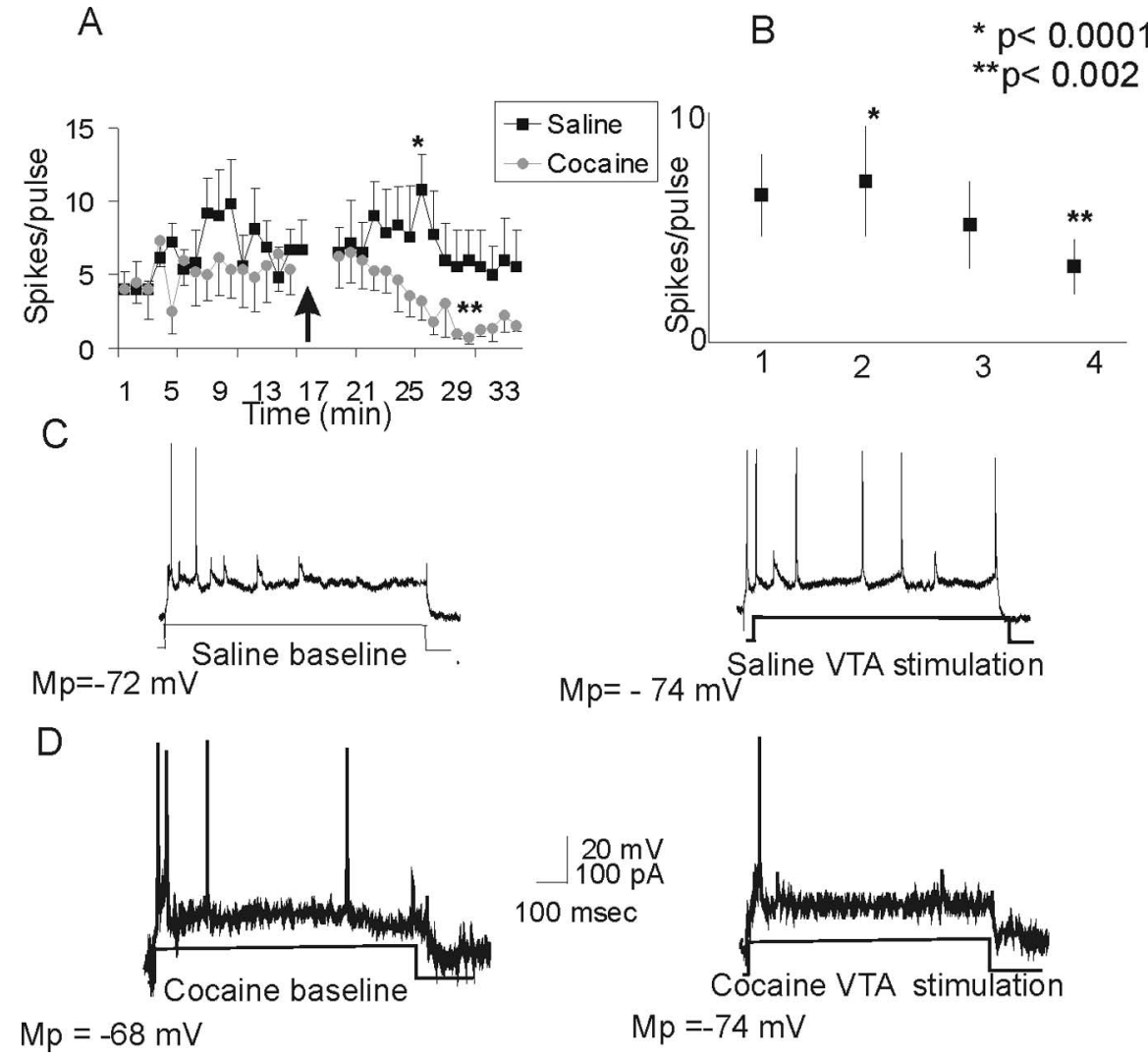

Figure 3. Electrical stimulation of the VTA differentially affects current-evoked cortical excitability in saline- and cocainetreated animals. A, Stimulation of the VTA with a train of pulses $(20 \mathrm{~Hz} / 2 \mathrm{~s})$ induced a significant long-lasting increase in cortical excitability in saline-treated rats $(p<0.0001 ; n=4)$. However, the same protocol induced a significant decrease in cortical excitability in the cocaine-treated group ( $p<0.002 ; n=8$ ). The arrow indicates stimulation of the VTA. $\boldsymbol{B}$, Graph depicting the average changes in excitability elicited by VTA stimulation in the saline- and cocaine-treated groups. 1 , Saline baseline; 2 , saline plus VTA stimulation; 3, cocaine baseline; 4, cocaine plus VTA stimulation. C, Representative traces from a saline-treated animal illustrating the increase in the number of current-evoked spikes after VTA stimulation. $\boldsymbol{D}$, Representative traces from a cocainetreated animal illustrating the decrease in the number of current-evoked spikes after VTA stimulation. Mp, Membrane potential.

increase in the current-evoked excitability in the saline-treated group. In contrast, the excitability decreased in response to sulpiride in the cocaine group $\left(F_{(1,21)}=8.1 ; p<0.009\right)$ (Fig. $\left.2 B\right)$.

\section{Effects of VTA stimulation on current-evoked excitability}

Similar to reports in drug-naive animals (Lavin et al., 2005), a train of stimulation delivered into the VTA induced a longlasting increase in the current-evoked excitability of PFC neurons in the saline-treated group (Fig. 3). Whereas saline-exposed rats showed an increase in current-evoked excitability after VTA stimulation, cocaine-treated animals showed a significant decrease in excitability after stimulation $(p<0.002)$ (Fig. 3). A repeated-measures ANOVA revealed a significant effect of group $\left(F_{(1,30)}=11.2 ; p<0.0022\right)$ and an interaction between group and treatment $\left(F_{(1,30)}=23.8 ; p<0.0001\right)$.

\section{Effects of VTA stimulation on spontaneous activity}

Akin to reports in the literature using extracellular unit recordings in naive animals (Bunney and Aghajanian, 1979; Sesack and Bunney, 1989), VTA stimulation reduced the spontaneous firing frequency of PFC neurons in both saline- and cocaine-treated animals. An ANOVA revealed a significant effect of VTA stimulation $\left(F_{(1,26)}=5.7 ; p<0.002\right)$ (Fig. 4$)$, but there was no significant effect of cocaine or interaction between cocaine and VTA stimulation.

\section{Discussion}

Our results indicate a lack of responsivity to $\mathrm{D}_{2}$ modulation of current-evoked activity in cortical pyramidal cells after $2-4$ weeks of withdrawal from repeated treatment with cocaine. Furthermore, contrary to what has been found in naive and in saline-treated animals, stimulation of the VTA decreased current-evoked excitability in cocaine-treated rats. These data suggest that repeated cocaine administration alters intrinsic currents in pyramidal neurons and also alters dopaminergic signaling in the PFC.

\section{Effects of $D_{1}$ and $D_{2}$ receptor antagonists on cortical cell activity} In saline- and cocaine-treated rats, administration of the selective $D_{1}$ receptor antagonist SCH 23390 decreased currentevoked excitability. This effect of the $\mathrm{D}_{1}$ receptor antagonist on PFC activity has been demonstrated previously in naive animals (Yang and Seamans, 1996; Shi et al., 1997; Henze et al., 2000; Lavin and Grace, 2001; Wang and O'Donnell, 2001; Lavin et al., 2005). Our results show that salineand cocaine-treated animals exhibit a reduction in current-evoked firing after systemic administration of $D_{1}$ receptor antagonists, suggesting that neither $D_{1}$ receptor responsivity nor DA action on $\mathrm{D}_{1}$ receptors is affected by withdrawal from chronic cocaine. It is important to note that, in a group of experiments, we used intravenous administration of SCH 23390 at a dose of $1.0 \mathrm{mg} / \mathrm{kg}$. Although this dose has been widely used in electrophysiological and behavioral experiments assessing $D_{1}$ receptor activity, it has also been reported to interact with serotonin receptors (Lewis and O'Donnell, 2000; Brady and O'Donnell, 2004; Daniela et al., 2004). Therefore, we also tested SCH 23390 at doses of $0.1 \mathrm{mg} / \mathrm{kg}$ intravenously. It was found that, in saline- and cocaine-treated animals, lower doses of SCH 23390 decrease current-evoked excitability.

Our experiments show that cocaine pretreatment abolished the effects of the $\mathrm{D}_{2}$ antagonist sulpiride. In saline-treated rats as well as in naive animals (Lavin et al., 2005), systemic administration of the selective $\mathrm{D}_{2}$ receptor sulpiride increased the currentevoked firing of cortical cells. In contrast, sulpiride failed to increase cortical excitability in cocaine-withdrawn animals. Indeed, even when higher doses of sulpiride $(15 \mathrm{mg} / \mathrm{kg})$ were tested, the $\mathrm{D}_{2}$ antagonist failed to induce an increase in the current-evoked excitability of cortical neurons. The relatively pronounced effect of cocaine on $D_{2}$ versus $D_{1}$ antagonists is consistent with a recent report showing that withdrawal from cocaine markedly upregulates the activator of G-protein signaling AGS3 (Bowers et al., 2004). The upregulation of AGS3 selectively limits $D_{2}$ signaling via $G_{i}-$ coupled receptors without affecting $D_{1} G_{s}$ signaling (Blumer et al., 2002; Bowers et al., 2004), and, after withdrawal from chronic cocaine, the upregulation of AGS3 in the PFC inhibited $\mathrm{D}_{2}$ agonist-induced GTP $\gamma \mathrm{S}$ binding (Bowers et al., 2004). 
A sizable body of evidence describes the fundamental role of $\mathrm{PFC} \mathrm{D}_{2}$ receptors in cocaine addiction. Beyer and Steketee (2002) demonstrated that intra-mPFC injections of the $\mathrm{D}_{2}$ receptor agonist quinpirole blocked cocaine-induced sensitization. Moreover, in studies with human addicts, Volkow et al. (2001) reported lower levels of $\mathrm{D}_{2}$ receptor availability in the orbitofrontal cortex, suggesting that dysregulation of this type of receptor could underlie the loss of control and compulsive drug intake in drug addicts.

Although we have interpreted our findings in terms of direct effects by DA antagonists in the PFC, it is important to be mindful that, in these experiments, the DAergic antagonists were injected systemically. Thus, DA receptors in other parts of the corticolimbic circuit in which the PFC is embedded were also blocked, and a definitive assertion that DA receptors in PFC were solely responsible for the observed effects cannot be made.

\section{Repeated treatment with cocaine} depresses evoked cortical excitability A train of stimuli delivered into the VTA induced a long-lasting increase in currentevoked excitability coupled to a decrease in spontaneous activity in the PFC of saline-treated or drug-naive rats (Lavin et al., 2005). This is consistent with both in vitro intracellular/patch-clamp data showing a DA-mediated increase in currentevoked excitability and in vivo extracellular recordings revealing a DA-dependent reduction in spontaneous firing (for review, see Seamans and Yang, 2004). This opposing action on spontaneous versus current-evoked firing is presumably attributable to the modulation of multiple PFC currents by DA and was directly predicted by network models incorporating such complex modulations (Durstewitz et al., 2000). Our results show that cocaine treatment abolished the VTA-mediated increase in current-evoked excitability but did not affect the VTA-mediated decrease in spontaneous activity. These results suggest that, besides affecting responsivity to $\mathrm{D}_{2}$ receptor antagonists, cocaine treatment is affecting intrinsic currents in cortical cells. Arguing against this possibility, recent studies in dissociated PFC pyramidal cells after withdrawal from cocaine demonstrate increased excitability as a result of a decreased voltage-gated and inwardly rectifying $I_{\mathrm{k}}$ and enhanced L-type $I_{\mathrm{Ca} 2+}$ (Dong et al., 2005; Nasif et al., 2005a). Moreover, Nasif et al. (2005b) showed that repeated cocaine administration increased the membrane excitability of PFC neurons in slices. The apparent contradictory findings on excitability between recordings in vitro and in vivo suggest that cocaine-induced neuroadaptations in the circuit in which the PFC pyramidal cells are embedded are critically affecting excitability. Moreover, our experiments were performed after 2 weeks of withdrawal, and the recordings were performed in adult animals ( 3 months old) versus the young animals used in brain slices or dissociated cell preparations (4-6 weeks old). As indicated herein, altered signaling through $\mathrm{D}_{1}$ versus $\mathrm{D}_{2}$ constitutes one cocaine-induced adaptation that could alter excitability in pyramidal cells.

\section{Conclusions}

The balance between $\mathrm{D}_{1}$ and $\mathrm{D}_{2}$ receptors contributes to optimal cortical function. The reduction in responsiveness to $\mathrm{D}_{2}$ receptor antagonists in cocaine-withdrawn animals is consistent with previously reported increases in AGS3 content in the PFC of cocaine withdrawn rats that selectively reduce GTP $\gamma \mathrm{S}$ binding induced by $\mathrm{D}_{2}$ but not $\mathrm{D}_{1}$ receptors (Bowers et al., 2004). Also, these findings are consistent with the reduction in cortical $\mathrm{D}_{2}$ receptors and the overall prefrontal cortical hypoactivity reported to occur in cocaine addicts (Grant et al., 2000; Goldstein and Volkow, 2002). Together, these data indicate that the dysfunction of the PFC implicated in psychostimulant addiction (Jentsch and Taylor, 1999; Berke and Hyman, 2000; Kalivas et al., 2005) may in part result from reduced $D_{2}$ signaling and reduced excitability of pyramidal cells. Future studies will have to be performed in rats trained to self-administer cocaine to investigate the contributions of contingent versus noncon- 
tingent drug administration, as well as in animals undergoing a broader range of withdrawal periods.

\section{References}

Berke JD, Hyman SE (2000) Addiction, dopamine, and the molecular mechanisms of memory. Neuron 25:515-532.

Beyer CE, Steketee JD (2002) Cocaine sensitization: modulation by dopamine D2 receptors. Cereb Cortex 12:526-535.

Blumer JB, Chandler LJ, Lanier SM (2002) Expression analysis and subcellular distribution of the two G-protein regulators AGS3 and LGN indicate distinct functionality. Localization of LGN to the midbody during cytokinesis. J Biol Chem 277:15897-15903.

Bowers MS, McFarland K, Lake RW, Peterson YK, Lapish CC, Gregory ML, Lanier SM, Kalivas PW (2004) Activator of G protein signaling 3: a gatekeeper of cocaine sensitization and drug seeking. Neuron 42:269-281.

Brady AM, O'Donnell P (2004) Dopaminergic modulation of prefrontal cortical input to nucleus accumbens neurons in vivo. J Neurosci 24:1040-1049.

Brady AM, Glick SD, O’Donnell P (2005) Selective disruption of nucleus accumbens gating mechanisms in rats behaviorally sensitized to methamphetamine. J Neurosci 25:6687-6695.

Bunney BS, Aghajanian GK (1977) Electrophysiological studies of dopamine-innervated cells in the frontal cortex. Adv Biochem Psychopharmacol 16:65-70.

Daniela E, Brennan K, Gittings D, Hely L, Schenk S (2004) Effect of SCH 23390 on ( \pm )-3,4-methylenedioxymethamphetamine hyperactivity and self-administration in rats. Pharmacol Biochem Behav 77:745-750.

Dong Y, Nasif FJ, Tsui JJ, Ju WY, Cooper DC, Hu XT, Malenka RC, White FJ (2005) Cocaine-induced plasticity of intrinsic membrane properties in prefrontal cortex pyramidal neurons: adaptations in potassium currents. J Neurosci 25:936-940.

Durstewitz D, Seamans JK, Sejnowski TJ (2000) Dopamine-mediated stabilization of delay-period activity in a network model of prefrontal cortex. J Neurophysiol 83:1733-1750.

Goldstein RZ, Volkow ND (2002) Drug addiction and its underlying neurobiological basis: neuroimaging evidence for the involvement of the frontal cortex. Am J Psychiatry 159:1642-1652.

Goto Y, Grace AA (2005) Dopamine-dependent interactions between limbic and prefrontal cortical plasticity in the nucleus accumbens: disruption by cocaine sensitization. Neuron 47:255-266.

Grace AA (2000) The tonic/phasic model of dopamine system regulation and its implications for understanding alcohol and psychostimulant craving. Addiction 95 [Suppl 2]:S119-S128.

Grant S, Contoreggi C, London ED (2000) Drug abusers show impaired performance in a laboratory test of decision making. Neuropsychologia 38:1180-1187.

Hedou G, Homberg J, Feldon J, Heidbreder CA (2001) Expression of sensitization to amphetamine and dynamics of dopamine neurotransmission in different laminae of the rat medial prefrontal cortex. Neuropharmacology 40:366-382.

Henze DA, Gonzalez-Burgos GR, Urban NN, Lewis DA, Barrionuevo G (2000) Dopamine increases excitability of pyramidal neurons in primate prefrontal cortex. J Neurophysiol 84:2799-2809.

Jentsch JD, Taylor JR (1999) Impulsivity resulting from frontostriatal dysfunction in drug abuse: implications for the control of behavior by reward-related stimuli. Psychopharmacology 146:373-390.

Kalivas PW, Volkow N, Seamans J (2005) Unmanageable motivation in addiction: a pathology in prefrontal-accumbens glutamate transmission. Neuron 45:647-650.
Lavin A, Grace AA (2001) Stimulation of $\mathrm{D}_{1}$-type dopamine receptors enhances excitability in prefrontal cortical pyramidal neurons in statedependent manner. J Neurosci 104:335-346.

Lavin A, Nogueira L, Lapisch C, Wightman M, Phillips P, Seamans JK (2005) Mesocortical dopamine neurons operate in distinct temporal domains using multimodal signaling. J Neurosci 25: 5013-5023.

Lewis BL, O'Donnell P (2000) Ventral tegmental area afferents to the prefrontal cortex maintain membrane potential "up" states in pyramidal neurons via $\mathrm{D}(1)$ dopamine receptors. Cereb Cortex 10:1168-1175.

Marsteller DA, Gerasimov MR, Schiffer WK, Geiger JM, Barnett CR, Borg JS, Scott S, Ceccarelli J, Volkow ND, Molina PE, Alexoff DL, Dewey SL (2002) Related acute handling stress modulates methylphenidateinduced catecholamine overflow in the medial prefrontal cortex. Neuropsychopharmacology 27:163-170.

Nakamura K, Shirane M, Koshikawa N (2001) Site-specific activation of dopamine and serotonin transmission by aniracetam in the mesocorticolimbic pathway of rats. Brain Res 897:82-92.

Nasif FJ, Hu XT, White FJ (2005a) Repeated cocaine administration increases voltage-sensitive calcium currents in response to membrane depolarization in medial prefrontal cortex pyramidal neurons. J Neurosci 25:3674-3679.

Nasif FJ, Sidiropoulou K, Hu XT, White FJ (2005b) Repeated cocaine administration increases membrane excitability of pyramidal neurons in the rat medial prefrontal cortex. J Pharmacol Exp Ther 312:1305-1313.

Paxinos G, Watson C (1998) The rat brain in stereotaxic coordinates. Ed 4. San Diego: Academic.

Peterson JD, Wolf ME, White FJ (2000) Altered responsiveness of medial prefrontal cortex neurons to glutamate and dopamine after withdrawal from repeated amphetamine treatment. Synapse 36:342-344.

Phillips AG, Ahn S, Floresco SB (2004) Magnitude of dopamine release in medial prefrontal cortex predicts accuracy of memory on a delayed response task. J Neurosci 24:547-553.

Pierce RC, Bell K, Duffy P, Kalivas PW (1996) Repeated cocaine augments excitatory amino acid transmission in the nucleus accumbens only in rats having developed behavioral sensitization. J Neurosci 16:1550-1560.

Seamans JK, Yang CR (2004) The principal features and mechanisms of dopamine modulation in the prefrontal cortex. Prog Neurobiol 74:1-58.

Sesack SR, Bunney BS (1989) Pharmacological characterization of the receptor mediating electrophysiological responses to dopamine in the rat medial prefrontal cortex: a microiontophoretic study. J Pharmacol Exp Ther 248:1323-1333.

Shi WX, Zheng P, Liang XF, Bunney BS (1997) Characterization of dopamine-induced depolarization of prefrontal cortical neurons. Synapse 26:415-422.

Trantham H, Szumlinski KK, McFarland K, Kalivas PW, Lavin A (2002) Repeated cocaine administration alters the electrophysiological properties of prefrontal cortical neurons. Neuroscience 113:749-753.

Volkow ND, Chang L, Wang GJ, Fowler JS, Ding YS, Sedler M, Logan J, Franceschi D, Gatley J, Hitzemann R, Gifford A, Wong C, Pappas N (2001) Low level of brain dopamine D2 receptors in methamphetamine abusers: association with metabolism in the orbitofrontal cortex. Am J Psychiatry 158:2015-2021.

Wang J, O’Donnell P (2001) D1 dopamine receptors potentiate NMDAmediated excitability increase in layer $\mathrm{V}$ prefrontal cortical pyramidal neurons. Cereb Cortex 11:452-462.

Yang CR, Seamans JS (1996) Dopamine $\mathrm{D}_{1}$ receptor actions in layer V-VI rat prefrontal cortex neurons in vitro: modulation of dendritic-somatic signal integration. J Neurosci 16:1922-1935. 